\title{
Scoring System Improvements to Three Leadership Predictors
}

Michelle R. Dela Rosa

Human Resources Research Organization

Deirdre J. Knapp

Human Resources Research Organization

Brian D. Katz

Human Resources Research Organization

Stephanie C. Payne

George Mason University

Consortium Research Fellows Program

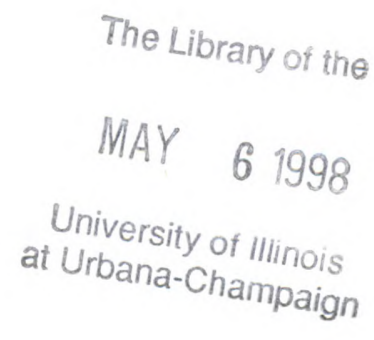

September 1997

United States Army Research Institute for the Behavioral and Social Sciences 